\title{
Towards a Research Agenda on Individual Differences in ELT in Nigeria ${ }^{1}$
}

\begin{abstract}
There are a variety of individual differences that English language teaching (ELT) professionals cannot afford to ignore. This essay is based on a premise that teaching and learning English in Nigeria's multilingual background of 526 languages (Ethnologue, 2018) present an extraordinary context of multiculturalism and individual differences in the language classroom. ELT professionals in such a context require significant expertise in the application of inclusive practices. The essay identified gaps in the praxis and policy dimensions of Nigerian ELT practice relating to individual differences and suggested a research focus on these two areas. It concluded that teachers should adopt clear, empirically tested methodologies to cater for the different students in the class, create good relationships in the classroom to develop learner self-confidence, integrate activities and tasks that clearly appeal to different learning styles and personalities, personalize learning as much as possible, create learner autonomy, and pay attention to cultural variations among L2 learners.
\end{abstract}

KEYWORDS: individual differences, English in Nigeria, learning strategies, affective factors, L2.

\section{Introduction}

In learning a given language, certain variables account for the rate and speed at which learning tasks are attained. These differences are marked in individuals to the extent that in a class of as few as ten learners, sharp differences may abound in the level of acquisition, if measured, at the end of a well delivered lecture.

By individual differences in learning, we are referring to specific factors in the individual learner, which account for the rate at which such a person learns and attains a high level of competence in that task or fails to do so. It

1 This paper is dedicated to the memory of late Dr Isaac Tamunobelema, who passed on after contributing to the initial draft. 
has been observed that in the same learning environment, some learners are more successful than others, and Richards and Schmidt (2012) noted that individual learner factors have been frequently identified as the possible causes of differential success rates. Some of these categories of learner difference areas include age, sex, attitude, motivation, cognition style, learning strategies and personality traits.

\section{Theoretical Framework}

This essay is based on Robert Sternberg's Triarchic Theory of Intelligence also known as the Theory of Three Forms of Intelligence. The theory proposed three distinct types of intelligence (practical intelligence, creative intelligence, and analytical intelligence) that humans can possess and these account for the differences in the ways that individuals learn and the need for inclusive practices that integrate these in teaching and assessment. The theory consists of three categories of sub-theories: the contextual, the componential, and the experiential.

1. The contextual sub-theory views intelligence as relative to the sociocultural situation of an event: what passes as an act of intelligence in a context at one place may not pass as same in similar context at another place. Intelligent behaviour is determined by both the event and the external world where it happened. Contextual intelligence therefore involves the modification of the present environment to make it more favourable, the adaptation to a new environment, and the selection of a more favourable environment.

2. The componential sub-theory specifies that metacognitive, performance, or knowledge acquisition components underpin intelligent behaviour. These structures and mechanisms constitute the potential set of mental processes that underpins human behavior.

3. The experiential sub-theory specifies that intelligent behavior should be referenced as cumulative of experience from the unknown to the familiar. It determines intelligence by considering the relationship between the level of experience the individual possesses and the individual's behavior in the same task.

Based on the Triarchic Theory of Intelligence, a comprehensive evaluation of human intelligence requires the consideration of these three 
sub-theories. The theory stipulated the following principles for its operation (Culatta, 2020):

1. Training for intellectual performance must be both socially and culturally relevant to the needs of the individual trainee.

2. A training program should provide links between the training and real-world behavior.

3. A training program should provide explicit instruction in strategies for coping with novel tasks/situations.

4. A training program should provide explicit instruction in both executive and non-executive information processing and interactions between the two.

5. Training programs should actively encourage individuals to manifest their differences in strategies and styles.

The consciousness of these principles will enable teachers to make appropriate selection of materials, activities, and methodologies during lesson planning. Overall, the principles of the Triarchic Theory of Intelligence enhance learning outcome by emphasizing both the relevance of learning experience and inclusive practices.

\section{Literature Review: Traits of Individual Differences in Learners}

Learner differences have left language practitioners in search of possible solutions and these problems are descriptive, theoretical and practical in nature. The descriptive perception is related to how best to research and categorize the differences between learners, and the relationship between those differences and the achievement of greater learning objectives. The theoretical dimension is related to the relevance of those differences in actual second language learning situations. The practical questions border on how to design instruction that would best capture the contributions of each variable in the learning process. Some of these individual variables can be voluntarily controlled while others cannot be similarly controlled. For example, age and cognitive traits are outside the experience of the applied linguist who may not be able to do anything to change them. On the other hand, learning styles, preferences and cultures are amenable to changes in the hand of the practitioner who is aiming at achieving greater learning outcomes. 


\subsection{Age}

Age difference in learning a language is a controversial issue because, while some practitioners believe that the younger the learner, the better the learning takes place, others believe in the contrary. One of the theories in this regard is the Critical Period Hypothesis ( $\mathrm{CPH}$ ), which proposed that younger children naturally and quickly acquire language more easily between ages 0 and 9 years and tend to lose that ability later in life (Penfield \& Roberts, 1959). Sebastian-Galles, Echererria, and Laura (2005); Harley (1986); Scherage et al. (2004) take into account age difference in relation to individual's reproductive fitness, inherent nature of the learner, environment, and cost and consider the critical period as an adaptive mechanism, keeping all other factors in equilibrium, which determines optimal reproductive success in the language user.

Some language acquisition practitioners have argued that results in critical period apply to only first language context and that in second language situation, older students learn better than younger ones (Snow \& Hoefnagel-Hoehle, 1975; Swaine, 2000). Ur (2012) adduced certain reasons to support the above assertion and some of them include motivation and cognitive ability of the learner. However, the age factor, viewed from any angle has implications for the practicing applied linguist since rate and speed of acquisition will definitely vary among learners of different ages.

\subsection{Culture}

In learning English, whether as a foreign or second language, individual differences in terms of culture must be considered since it is not possible to have homogeneity in learners' culture. Culture, here refers to the total social behavior, experience and background of the individual learning a language. These cultural differences of the individuals may cause problems, because learners tend to incorporate elements of these into their behavioral repertoires (Kobayashi \& Viswat, 2007) including their use of language. Studies conducted to identify the cultural differences between Japanese and American students in four areas have shown that students' attitudes towards discussion, approach to problems, approach to competition, and pragmatic values in learning styles vary considerably (Stewart \& Bennett, 1991; Samovar \& Porter, 2001; Fink, 2003). The four areas covered in the studies are namely: differences in students' attitudes towards discussion, differences in ways of voicing objections to teachers remarks, differences in views about competition, and differences in views about efficiency, 
However, what a language teacher does with the marked cultural differences in the class is a central issue in Applied Linguistics (Pica, 1994). In a way, it has been postulated that cultural differences can result in two kinds of motivation, namely: integrative and instrumental motivation (Gardner \& Lambert, 1972). The former refers to the ability of a language learner to acquire the language at the same time immersing self into the whole culture of the language. The latter refers to the functional need the learner has to acquire the language in order to serve some utilitarian purpose, such as securing a job. But despite the fact that both kinds of motivation in learning a language cannot be separated, they are putatively linked. Language is alive, not dead and is not divorced from the culture that produced it (Tang, 1999). Consequently, it is the responsibility of the teacher in the classroom to exploit these numerous cultural varieties for effective language learning.

\subsection{Gender}

Gender differences in language learning have attracted numerous investigations with a view to enhance language learning and linguistics. Saville-Troike (2012) and Kimura (1999) have made inputs into the body of research in sexual differences among learners of language. Zoghi, Kazemi, \& Kalani (2013) observed that the females in their study population performed better in English as foreign language (EFL) learning than the males in the study. It has also been argued that females are less asymmetrical for speech, are better at memorizing complex linguistic forms, have high estrogen levels, which correlates with better semantic and interpretive skills, and possess a high verbal fluency in communication. Similar works in the areas cover differences in sex behavior, intelligence, memory, aggression, personality traits, empathy, emotion, ethics and moral orientation, mental health and cognitive skills (Saville-Troike, 2012).

A recent investigation carried out by Nima, Parviz, and Parviz (2016) showed that male and female brains biologically do not have the same floor plan. They posited that female brains process language activities more easily, earlier, and faster than males, while males more readily excel at spatial-mechanical and gross motor skill tasks. Similarly, Gurian and Stevens (2004) examined the characteristics of girls' brain and that of the boys and concluded that girls do better than boys in reading and writing, while boys tend to gravitate towards motor activities. Also, the report indicated that because of the presence of high amount of white matter in corpus callosum, female brains enjoy a high degree of bilateralization than 
boys. This, according to the investigation account for females excelling in communication practices. Knowledge of both sexes in this regard will enable the classroom teacher to explore possible avenues to close the gap in the acquisition of second language.

\subsection{Learning styles}

Cognitive style and cognitive strategies are terms, which have been used interchangeably with learning style, a term that first appeared in language learning in 1954 (Thelen, 1954). Learning style is used to describe a particular way in which a learner prefers to learn something (Richards \& Schmidt, 2012). The terms are used to designate the preferred forms of brain activity associated with information acquisition and processing and consider personality variables to represent another kind of learning style (Ehrman, 2001). Learning style conjures the idea of the individual's natural, habitual and preferred way of absorbing, processing and retaining new information and skills in the environment.

It is quite usual to note that in second or foreign language learning, learners adopt varied means of solving their learning problems. For instance, a learner may prefer explanation to grammatical rules, such as the notion of grammatical concords. Another may be more comfortable with explanation and writing down illustrative sentences on the chalkboard. Yet, some others may remember those lessons and apply them in daily use when explanations go with pictorial associations. These ideas buttress the claim that it is wrong to expect uniformity in gaining proficiency or success in a particular field, especially in language studies from a group of students due to learners' background, intelligence, interest, aptitude and so on.

Researchers and practitioners use learning style research with personality and cognitive styles to determine ability, predict performance and improve classroom teaching and learning (Ehrman \& Oxford, 1995; Erhman, 2001; Ehrman, Learner \& Oxford, 2003). Richards and Schmidt (2012, p. 85) have identified several different dimensions of cognitive styles namely:

1. Analytical versus global styles where the learners focus or concentrate on the details of the main idea or big picture.

2. Visual versus auditory vs. hands-on or tactile styles which refers to different sensory preferences in learning.

3. Intuitive/random versus concrete/sequential learning which refers to a difference between thinking in an abstract or non-sequential 
way and. a focus on a concrete fact or a preference to approach learning in a step by step, organized fashion. Learning styles theory contributes in no small way to the way students succeed or otherwise in approaching learning in their different styles.

\subsection{Learning Strategies}

The theory of learning strategies has a clear, unambiguous concept distinguishing it from others, such as learning styles. A learning strategy is the way in which learners attempt to work out the meanings and uses of words, grammatical rules, and other aspects of the language they are learning (Richards \& Schmidt, 2012). In a second language learning situation, it is pertinent to add that a strategy is always an intentional behavior carried out by a learner with a view to achieving success in language learning. However, the efficiency of a given learning strategy, that is, whether it is good or bad is considered in relation to the context of use.

Ehrman and Oxford (1995) stated certain conditions under which a strategy is regarded as useful. They include: (1) the strategy must fit into the learning style of the students in a certain degree, (2) the strategy must be seen to be related to the $L_{2}$ learning task ahead, and (3) the learners must be able to employ the strategy effectively, relating it to other learning situations. In her view, if a strategy meets these conditions, learning becomes easier, faster, more enjoyable, more effective, and even more transferable to new situations. An effective strategy promotes learner independence and autonomy, which are pedestals of lifelong learning.

Instructions on language learning strategies dominate the field of Applied Linguistics and the theories of language learning. Ehrman (1996); Cohen (1998); and Wenden \& Rubin (1987) are among leading contributors to the literature. Erhman, Learner and Oxford (2013) identified six main groups of learning strategies. They are:

1. Cognitive strategies, in which the learner manipulates language materials directly through reasoning, analyzing, note-taking and synthesizing.

2. Meta-cognitive strategies imply being aware of one's learning, planning and monitoring one's progress.

3. Social strategies involve asking questions, seeking clarification, asking for help, talking with native-speaking persons, or working with peers in a classroom setting and desiring to learn through interaction. 
4. Memory-related strategies help learners link one $\mathrm{L}_{2}$ item with another, with deep understanding such as images, acronyms, sounds, similarities, and so on.

5. Compensatory strategies help make up for the mixing knowledge such as guessing from the context, circumlocution, gestures and pause word.

6. Affective strategies which identify one's mood and anxiety and help learners manage their emotions and motivational levels. These and many other strategies are guidelines for teachers and students alike for choosing and using the appropriate strategies for the enhancement of language learning.

7. Affective Factors: Literature in affective domain is rife in language learning since about the 1950 s and motivation is the most commonly investigated factor.

In its simplest sense, affective factors have objectives tilted towards development in students' attitudes, feelings and values. Besides motivation, self-efficacy, tolerance of ambiguity, anxiety and the likes are included. Motivation in learning has been classified into domains. In Gardner's $(1985 ;$ 1988) Socio-educational model of language learning, we have integrative and instrumental motivations. Integrative orientation is wanting to learn language for the access it gives to the culture of the other community with a desire to participate as a member of it. Instrumental orientation on the other hand, entails gaining benefits essentially within one's own culture from speaking another language, such as career advancement, societal esteem, education, and so on.

There are numerous investigations of the integrative and instrumental orientations in their various nomenclatures. For instance, Clement, Dornyei \& Noels (1994) identified five orientations of foreign language learners. In their view, some of the reasons for learning a second language include: (a) friendship and travel-related (b) identification with a foreign culture, (c) identification with the target language group, (d) expansion of knowledge of the world and career improvement and (e) a desire to be acquainted with the media of the target language. Deci and Ryan (1985) also researched along intrinsic and extrinsic motivation where it is stated that the former comes from within the individual and with a sense of self identity and well-being. But the later (extrinsic) is external, which entails learning the foreign language for the sake of reward. Many language learning philosophers have argued that intrinsic motivation correlates more closely with language learning success 
(Walqui, 2000), but it must be emphasized that students' motivation is often a combination of both.

Despite motivation as a factor for learning, other affective factors include: anxiety (Dickson, 1995), internal attitudes (Crooke \& Schmidt, 1991), self-management, self-monitoring (Krashen, 1981), emotional intelligence (Goleman, 1995), and others. All these factors are somehow related to motivation and all play an important role in either promoting or hindering learning by an individual. It is therefore necessary to reiterate, even at the risk of repetition, that findings in motivation in affective factors in learning have not been unanimous. Walqui (2000) disagreed with the view that integrative orientation is far less important in foreign language setting. The same also goes for other affective variables such as anxiety, internal attitudes and self-monitoring.

The literature reviewed above established the relevance of individual differences in English language teaching (ELT) and the contributions it could make to language learning. The learning of English would therefore be enhanced if teachers of English are aware of the concept of individual differences and apply its principles in teaching their learners.

\section{The Language Situation in Nigerian Classrooms}

In Nigeria's multilingual context of approximately 526 languages, differences in learner attitude are further multiplied by the implicit multicultural background the learners bring along with their native languages to the classroom. The National Policy on Education (NPE) (FRN 2013) introduced another dimension to the challenges of coping with individual differences. Section 2(20) of the policy provided that "The medium of instruction in the primary school shall be the language of the environment for the first three years in monolingual communities. During this period, English shall be taught as a subject." The policy provided further that teachers should transit to English as medium of instruction from Primary 4 up to the tertiary level. "Language of the environment" is a loose term in Nigerian cities where the English-based Nigerian Pidgin has significantly taken over the communicative roles of Nigerian native languages, which the policy formulators obviously referred to by the quoted term. Adherence to this provision is not strictly monitored and school operators choose whether to comply with the policy stipulations or to start their learners off with English as medium of instruction. This situation creates further challenges in 
individual difference among learner in terms of their periods of exposure to English as medium of instruction in higher classes. Teachers in higher levels of education receive learners who not only are instructed in an L2 as medium of instruction but also have disparate degrees of proficiency in that L2. ELT professionals in Nigeria can therefore turn to the application of individual differences pedagogy to enhance the learning experience of their students. We submit that significant literature on the subject support the following observations we make here about usefulness of individual differences in learning English in Nigeria:

- A sound knowledge of the principles of individual differences is necessary in lesson planning because modern classrooms are hardly homogenous in terms of linguistic background, age, sex, culture, and cognitive ability of the learners. Urban classroom in Nigeria especially manifest these diversities and require conscious efforts to deliver learning that integrates individual differences.

- The application of the principles of individual differences will enable the teacher to select appropriate materials, effective learning activities and tasks that would suit kinesthetic, auditory, tactile, and visual learners in the class.

- When teachers apply the principles of individual differences among learners of English, it inculcates the cherished ideals of equality, diversity, and inclusion (EDI) in the learners. This may become useful life-long learning on diversity and tolerance for students in Nigeria's multiethnic, multi-religious, and multilingual society. The application of yardsticks of individual differences regarding sex, age, culture, learning styles, etc. would reduce prejudices and promote learning in diversity and mutual respect among learners.

- Learning and practicing the principles of individual differences promotes fair and healthy competition among learners, who compete to achieve the highest outcomes for individual learners, contrary to unfair monolithic standards of achievement evaluation that breed jealousy, racism, resentment, sexism, and bullying.

- A teacher's mishandling of individual differences of learners could demotivate some learners and lead to unfair assessment of some learners based on their differences from a perceived "ideal" learner; rather than an appreciation of diversity of learner characteristics.

These observations are based on both our personal experiences of individual differences in teaching English as L2 in Nigeria and on the substantial review of literature presented above, in which authors generally 
lauded the benefits of inclusive integration of individual differences in the classroom. However, certain indices raise doubts regarding the level of awareness and practice of individual differences among teachers of English in Nigeria.

\section{Teaching and Learning English in Nigeria: Agenda on Individual Differences}

ELT in Nigeria offers more employment opportunities than any other single school subject and there is a constant high demand for teachers of the subject in the country. One of the consequences of these is a constant dearth of qualified teachers of English and a resultant employment of nonELT professionals to fill the gap. Consequently, graduates of non-teaching degrees, as well as graduates of disparate disciplines such as Sociology, Mass Communication, Political science, Theatre Arts, Geography, History, etc., are employed to teach English, especially in poorly regulated private primary and secondary schools across Nigeria. Obviously, these categories of teachers come unprepared for the task of handling learners' individual differences in terms of lesson delivery and assessment. Although this challenge may be applicable to the teaching and learning of other subjects in the Nigerian school system, our focus is on how it affects the learning of English. Applied linguists in Nigeria may direct more research focus on praxis and policy as two important foundations for a sustainable application of the principles of individual differences in ELT in Nigeria. Below are the details of our proposed research agenda and some justification for the ideas.

Firstly, praxis-based studies on teacher awareness and application of the principles of individual differences in learning delivery and assessment would enable applied linguists and English language teachers to determine both the challenges and the level of compliance of ELT professionals with the requirements of individual differences in teaching and learning English in Nigeria. It is important to re-examine the resources, theories, and processes of utilizing individual differences that could enhance the teaching and learning of English in Nigeria. This line of research will complement the abundant literature on individual differences in language learning. Teaching and learning an $\mathrm{L}_{2}$ in Nigeria's multilingual background of 526 languages present an extraordinary context of multiculturalism and individual differences in the language classroom. According to Ethnologue (2018), "The number of individual languages listed for Nigeria is 526 . Of these, 519 are living and 7 
are extinct. Of the living languages, 509 are indigenous and 10 are non-indigenous". Rural primary and community-based secondary schools would have less diversity than metropolitan schools and tertiary institutions, which generally have more diversity in learner backgrounds. The typical tertiary and urban classrooms in Nigeria are made up of learners from different ethno-linguistic and cultural backgrounds. What degree of awareness of cultural differences does an average teacher require to effectively reflect principles of EDI and avoid hurting cultural sensibilities? How do Nigerian teachers of English currently cope with learners from such widely divergent cultural background? In selecting cultural content, is it possible for teachers in this situation to integrate elements of the cultures of all the learners? If there are choices to be made, what are the criteria for either inclusion or exclusion of specific cultural contents?

Consequently, praxis-based research agenda on individual differences of Nigerian L2 learners should include resources that answer the questions raised in the preceding paragraph and similar ones for the ELT professional. The resources could be channelled towards assisting them in handling individual differences in their classes.

Stakeholder agencies should become proactive in issues of English and Nigerian indigenous languages in education. They could initiate studies and endowments on the different aspects of the subject and prepare a database of findings. Agencies such as the Nigerian Educational and Research Development Centre (NERDC), the Nigerian Council for Colleges of Education (NCCE), the National Universities Commission (NUC), and the National Institute for Nigerian Languages (NINLAN) could provide leadership on this agendum. Unfortunately, they have not provided curriculum guidelines on managing linguistic and cultural diversities in Nigerian classrooms. Rather than provide policy support for teachers on this subject, NERDC allowed Nigerian history (which could provide resource on cultural diversities for teachers and learners) to be expunged from the school curriculum for political reasons. Under the supervision of the NCCE, pre-service teacher education curriculum in the country is designed and operated along concepts of the teacher as insignificant social agent. Therefore, pre-service training (PRESET) of teachers is not accorded the same regiment of broad-based learning and extensive internship that is given to other important professions such as law, aviation, medicine, pharmacy, etc. In most cases, there are no opportunities of institutionalized in-service training (INSET) for teachers in Nigeria and the teachers are abandoned to self-help as primary means of professional development. 
Secondly, policy-based studies that may interface individual differences and learning outcome are required to provide clear policy dimension and professional guideline in the medium and the long terms. The national policy on education (NPE) provided that "Every child shall be taught in the mother tongue or the language of the immediate community for the first four years of basic education" (NPE, 2013, Section 1[8]). It went further to claim that "Government will ensure that the medium of instruction is principally the mother tongue (MT) of the learners or the language of the immediate community" (Section 2[16]) for early childhood care development. However, there are no adequate preparations and provisions to ensure effective implementation of this policy. For instance, the school curricula at that level have not been translated into the 509 native Nigerian languages that constitute the mother tongues and it is doubtful to us whether such a project would ever be accomplished in Nigeria's present political structure. Many of the native languages are not codified languages yet and many that are codified require further development to become useful in expressing mathematical and scientific concepts. Such a major policy required pilot studies, phased implementation, and perhaps, the creation of special PRESET curriculum to produce teachers that would implement it, while practicing teachers update their knowledge through INSET. Policy-based studies on the subject should address these gaps and adapt global best practices to suit Nigeria's context on the subject. It should also address the challenges of effective grading system in view of individual differences in $\mathrm{L}_{2}$ learning of English in Nigeria and determine the best method Nigerian institutions should use in achievement measurement.

Also, policy-based studies on individual differences should interrogate the factors responsible for any identified gaps between the theory and practice of the subject against the background of Nigerian educational system. They require a broad-based approach that would integrate infrastructure, manpower, policy, and environment in the interrogation. The studies may produce action plans and articulate recommendations for the government and the ELT professionals.

\section{Implications for Language Learning}

The traits of individual differences (age, sex, culture, learning styles, learning strategies and affective factors) affect learning in different ways. Bearing this in mind, applied linguists have proposed different ways of 
dealing with these differences in achieving good results in the classroom. Among them are, Dornyei and Csizer (1998) who proposed Ten Commandments, a number of activities which a practicing teacher should evolve in a second language learning situation. These are: personal examples; conducive atmosphere; proper presentation; good relationship; learner self-confidence, making the class interesting, promoting autonomy, personalizing instruction, good orientation, and paying attention to culture. They explained that if each of these factors comes to play in different circumstances in the context of demand, most of the learners' different needs should be met.

Individual differences can make a profound difference in teaching and learning of English. The awareness of the differences enables the teacher to manage the variables and perhaps, turn them into learning assets. The teachers' knowledge of the fact that the individual differences may result in different learning outcomes is a good starting point. Fink (2003) noted that recognizing each other's culture will prevent teachers and learners from imposing their own on others, allowing for individual pace and style in learning in the classroom.

In the affective domain, our emphasis is on intrinsic motivation, as a result of which the individual strives to learn the language because of a desire to do so and the satisfaction experienced in the learning task (Gardner, 1985). The teacher bears the responsibility of providing students with learning experiences that meet their needs for competence, relatedness, self-esteem and enjoyment. Also, the teacher can generate intrinsic motivation by allowing students to make choices thereby increasing their sense of autonomy which most learners' desire. It requires the teachers' expertise for flexibility and a clear syllabus that can provide for individual differences among students in $\mathrm{L}_{2}$ situation.

\section{Conclusion}

In this essay, we examined the traits of individual differences that have manifested among learners in $\mathrm{L}_{2}$ situations. We identified among others, differences in age, sex, culture, learning styles, learning strategies and affective factors. These factors lead to variations among learners in speed and rate of acquisition in language learning, and also enhance or hinder the learning processes depending on teacher roles. Language learners must be ready and have a clear reason for such a learning task. But it 
is the responsibility of the teacher, in many ways to guide the students to get the best out of learning. Based on the experiences in differences among individuals, the teacher should create the right atmosphere for language learning, where different learners would benefit. The teacher should adopt clear, empirically tested and acceptable teaching methods to take care of the different students in the class; create good relationships in the classroom where every student will develop self-confidence and integrate activities and tasks that clearly appeal to different learning styles and personalities. The teacher should, where appropriate personalize learning, create learner autonomy, and pay attention to cultural variations among $\mathrm{L}_{2}$ learners.

We have given a panoramic view of $\mathrm{L}_{2}$ learning of English in Nigeria and have also set two research agenda on individual differences in $\mathrm{L}_{2}$ learning of English in Nigeria. The agenda focus on the praxis of individual differences in the delivery and the assessment of learning of English in the Nigerian $\mathrm{L}_{2}$ classroom and on evolving lasting policy positions on the subject of diversity in education. We hope that both the review and the proposal espoused in this paper open up a vista for teachers to appreciate how different learners work, the similarities and differences among learners, and the teachers' reflection on how they have observed individual differences in their own practices.

\section{REFERENCES}

CLEMENT, R., DORNYEI, Z. \& NOELS, K. A. (1994) Motivation, self-confidence, and group cohesion in a foreign language classroom. Language learning. 44. Pp. 417- 448.

COHEN, A. D. (1998) Strategies for learning and using a second language. Essex, UK: Longman.

CROOKE, G. \& SCHMIDT, R. (1991) Motivation: reopening the research agenda. Language learning. 40. Pp. 45-78.

CULATTA, R. (2020) Triarchic Theory (Robert Sternberg). [Online] Available from: https://www.instructionaldesign.org/theories/triarchic-theory [Accessed: 27 June 2020].

DECI, L. \& RYAN, M. (1985) Intrinsic motivation and self-determination in human behaviour. New York: Plenum.

DICKSON, L. (1995) Autonomy and Motivation: A literature review. System. 23. Pp. 165174.

DORNYEI,Z. \& CSIZER, K. (1998) The Ten Commandments of motivating language learners: Results of an empirical study. Language Teaching Research. 2 (3). Pp. 203-229.

EHRMAN, M. E. \& OXFORD, R. L. (1995) Cognitive plus: Correlates of language learning success. Modern language journal. 79 (j). Pp. 67-88. 
EHRMAN, M. E. (1996) Understanding second language differences. C. A. Thousand Oaks: Sage.

EHRMAN, M. E. (2001) Bringing learning strategies to the learner: the ES1 language learning, consultation service. In: Alatis, J. E. \& Tan, A. (eds.) Language in our time: Bilingual education and official English, Ebonics and Standard English. Immigration and the Unz Initiative. Pp. 41-58. Cambridge, UK: Georgetown University.

EHRMAN, M. E., LEARNER, B. L. \& OXFORD, R. L. (2003) A brief overview of individual differences in second language learning. System. 31. Pp. 313-330.

Ethnologue (2018) Nigeria. [Online] Available from: https://www.ethnologue. com>country [Accessed: 6 December 2018].

FEDERAL REPUBLIC OF NIGERIA, THE. (2013) The National Policy on Education ( $3^{\text {rd }}$ ed.). Lagos: NERDC Press.

FINK, L. D. (2003) Creating significant learning experiences. C. A.: Jossey-Bass.

GARDNER, R. C. (1985) Socio-psychological and second language learning. London: Edward Arnold.

GARDNER, R. C. (1988) The socio-educational model of second language learning: Assumptions, findings and issues. Language learning. 35. Pp. 101-126.

GARDNER, R. C. \& LAMBERT, W. (1972) Attitudes and motivation in second language learning. Rowley, Massachusetts: Newbury House.

GOLEMAN, D. (1995) Emotional intelligence. New York: Bantam.

GURIAN, M. \& STEVENS, K. (2004) Educational leadership: With boys and girls in mind. [Online] Available from: www.ascd.org/publications/educational-leadership/ nor04/vol62/num03/with_boys_and_girls_in_mind [Accessed: 20 December 2016].

HARLEY, B. (1986) Age in second language acquisition. College-Hills Press. ISBN 9780-88744-269-8.

KIMURA, D. (1999) Sex and cognition. Cambridge: The MIT Press.

KOBAYASHI, J. \& VISWAT, L. (2007) Cultural differences in motivation to learning. [Online] Available from: http:/lites/j.org/Articles/Kobagashi-Cultural Differences in motivation to learning.html [Accessed: 10 October 2016].

KRASHEN, S. D. (1981) Second language acquisition and second language learning. Oxford: Pergamon.

NIMA, S., PARVIZ, M. \& PARVIZ, B. (2016) On revisiting the sex differences in language acquisition: An etiological perspective. [Online] Available from: https://www.researchgate.net/publication/305336069_on_Revisiting. [Accessed: 20 December 2016].

PENFIELD, W. \& ROBERT, L. (1959) Speech and brain mechanisms. Princeton: Princeton University Press.

PICA, T. (1994) Questions from the Language Classroom: Research perspectives. TESOL Quarterly. 28(i). Pp. 49-79.

RICHARDS, J. C. \& SCHMIDT, R. (2012) Longman dictionary of language teaching and applied linguistics. London: Person Education Limited.

ROBINSON, P. (2002) Individual Differences and Instructed Language Learning. Amsterdam: John Benjamins.

SAMOVAR, L. A. \& PORTER, R. E. (2001) Communication between cultures ( $4^{\text {th }}$ ed.). Belmont, CA: Wadsworth. 
SAVILLE-TROIKE, N. (2012) Introducing second language acquisition. Cambridge: Cambridge University Press.

SCHERAGE, A. et al. (2004) The effects of late acquisition of $\mathrm{L}_{2}$ and the consequences of immigration on $\mathrm{L}_{1}$ for semantic and morpho-syntactic language aspects. Cognition. 93 (3). Pp. 97-108.

SEBASTIAN-GALLES, N., ECHERERRIA, S. \& LAURA, B. (2005) The influence of initial exposure on lexical representation: Comparing early and simultaneous bilinguals. Journal of Language and Memory. 52 (2). Pp.240-255.

SNOW, C. \& HOEFNAGEL-HOEHLEM, M., (1978) The critical age of language acquisition: Evidence from second language learning. Child Development. 47. Pp. 1114-1128.

STEWART, E. C. \& BENNETT, M. (1991) American cultural patterns: A cross-cultural perspective. (Rev. ed.). Yarmouth: Intercultural Press.

SWAINE, M. (2000) French immersion research in Canada: Recent contributions to SLA and applied linguistics. Annual Review of Applied Linguistics. 20. Pp. 199-212.

TANG, R. (1999) The place of culture in the foreign language classroom: A reflection. [Online] Available from: http:/lites/j.org/Articles/Tang-Culture.html [Accessed: 10 October 2016].

THELEN, H. (1954) Dynamics of groups at work. Chicago: University of Chicago.

UR, P. (2012) A course in English language teaching. Cambridge: Cambridge University Press.

WALQUI, A. (2000) Contextual factors in second language acquisition. ERIC Digest. Washington, DC: ERIC Clearinghouse on Languages and Linguistics. Document ED444381.

WENDEN, A. \& RUBIN, J. (1987) Learner strategies in language learning. NJ, USA: Prentice Hall, Englewood Cliffs.

ZOGHI, M., KAZEMI, S. A. \& KALANI, A. (2013) The effect of gender on language learning. Journal of novel applied sciences. 1124-1128. [Online] Available from: www. jnasci.org [Accessed: 3 February 2017]. 